\title{
Kronik Hastalığı Olmayan Varikosel Tanılı Genç Erkek Hastalarda Kan Sayım Parametrelerinin Değerlendirilmesi
}

\author{
Evaluation of Blood Count Parameters in Young Male Patients with \\ Varicocele without Chronic Disease
}

\author{
Ali Aslan ${ }^{1}$, Abdullah Çırakoğlu ${ }^{2}$ \\ ${ }^{1}$ Ordu Üniversitesi, Tip Fakültesi, Fizyoloji AD, Ordu/ Türkiye \\ ${ }^{2}$ Ordu Üniversitesi, Tip Fakültesi, Üroloji AD, Ordu/ Türkiye \\ Yazısma Adresi / Correspondence: \\ Ali Aslan \\ Ordu Üniversitesi, Tip Fakültesi, Fizyoloji AD, Ordu/ Türkiye \\ T: +90452 $2265214 \quad$ E-mail : draslan@yahoo.com \\ Geliş Tarihi / Received : 16.07.2020 Kabul Tarihi / Accepted : 26.09.2020 \\ Orcid : \\ Ali Aslan https://orcid.org/0000-0002-9674-5618 \\ Abdullah Çırakoğlu https://orcid.org/0000-0002-8602-5836 \\ (Sakarya Tip Dergisi / Sakarya Med J 2020, 10(4):587-591 ) DOI: 10.31832/ smj.770022
}

\footnotetext{
$\ddot{O} z$

Amaç Varikosel pleksus pampiniformis içerisindeki testikuler venlerin anormal dilatasyonu olarak tanımlanan ve günümüzde erkeklerde infertiliteye neden olan en sik görülen hastalıklardan biridir. Çalışmamızın amacı varikosel tanısı alan hastalarda kan sayım parametrelerinin să̆lıklı bireylerle karşıllaştrıılmasısıı

Gereç ve Ordu Üniversitesi Eğitim ve Araștırma Hastanesi üroloji polikliniğine Nisan 2014-Nisan 2019 tarihleri arasında müracaat eden hastalar retrospektif olarak değerlendirildi.

Yöntem Fizik muayenesinde Grade 3 varikosel tanısı konulan 163 hasta saptandı. Dahil etme kriterlerini karsılayan toplam 112 hasta kontrol grubu olarak çalıșmaya alındı. Varikosel fizik muayene ile değerlendirildi. Elde edilen hemogram sonuçlarındaki beyaz kan hücresi, hemoglobin, Hematokrit, Platelet, Eritrosit, Nötrofil, Lenfosit, Monosit, Ortalama hemoglobin miktarı, Ortalama eritrosit hacmi (OEH), Eritrosit dağılım genişliği (EDG), Trombosit dağılım genişliği (TDG), Ortalama trombosit hacmi (OTH) değerleri karșılaștırıldı.

Bulgular Her iki grup arasında yas ortalamaları açısından istatistiksel farklılk saptanmamıstır ( $\mathrm{p}=0,370)$. Her iki grup arasında istatistiksel olarak anlamlı çkan parametreler sirasılla eritrosit $(\mathrm{p}=0,027), \mathrm{OEH}(\mathrm{p}=0,038), \mathrm{EDG}(\mathrm{p}=0,013)$ ve TDG $(\mathrm{p}=0,000)$ 'dır. OTH değeri kontrol grubuna göre varikosel grubunda istatistiksel anlamlllk olmasa da rakamsal olarak kontrol grubuna göre yüksek bulunmuștur. Diğer parametreler ve oranlar arasında istatistiksel açıdan anlamlı bir farklılık saptanmamıștır.

Sonuç Çalışmamız varikoseli olan hastalarda eritrosit, TDG ve EDG değerlerinin daha yüksek olduğunu göstermektedir. Trombosit ve eritrosit aktivasyonunun, varikoselin patofizyolojik temelinde önemli bir rol oynayabileceğini düşünmekteyiz.

Anahtar Varikosel; Trombosit; Eritrosit

Kelimeler

Abstract

Objective Varicocele is one of the most common causes of infertility in men today, which is defined as abnormal dilatation of testicular veins in plexus pampiniformis. The aim of our study was to compare blood count parameters with healthy subjects in patients with varicocele.

Materials Patients who applied to Ordu University Training and Research Hospital Urology Policlinic between April 2014 and April 2019 were evaluated retrospectively. In the physical examination, and methods 163 patients with Grade 3 varicocele were diagnosed. A total of 112 patients who met the inclusion criteria were included as a control group in the study. Varicocele was evaluated by physical examination. Obtained hemogram results in white blood cell, hemoglobin, hematocrit, platelet, erythrocyte, neutrophil, lymphocyte, Monocyte, mean erythrocyte volume, average hemoglobin amount, erythrocyte distribution width (RDW), platelet distribution width (PDW), mean platelet volume (MPV) values were compared.

Results There is no statistically significant difference was found between the two groups in terms of the mean age $(p=0.370)$. The statistically significant parameters between the two groups were erythrocyte ( $p=0.027), M C V(p=0.038), R D W(p=0.013)$ and $P D W(p=0.000)$, respectively. MPV values were higher in the varicocele group than the control group. There is no statistically significant difference was found between other parameters and rates.

Conclusion Our study shows that erythrocyte, PDW and RDW values are higher in patients with varicocele. We think that platelet and erythrocyte activation may play an important role in the pathophysiological basis of varicocele.

Keywords Varicocele; Platelet; Erythrocytes
} 


\section{GIIRIŞ}

Varikosel; pleksus pampiniformis içerisindeki testikuler venlerin anormal dilatasyonu olarak tanımlanan ve günümüzde erkeklerde infertiliteye neden olan en sık görülen hastalıklardan biridir. ${ }^{1}$

Primer (idiyopatik, sebebi bilinmeyen) ve sekonder olmak üzere 2 tip varikosel vardır. Primer varikosel, internal spermatik venlerdeki kapakçıkların yetersiz olması sonucu gelişir. Kan retrograd olarak pampiniform pleksusa reflü olur. Varikosel, erkeklerin yaklaşık \%15'ini etkilerken, infertilite polikliniğine başvuran erkeklerde bu oran \%40'a çımaktadır. ${ }^{2,3}$ Erkeklerde infertilitenin en sık düzeltilebilir sebebi varikoseldir. ${ }^{4}$ İnfertil erkeklerde ultrasonografi klinik olarak palpe edilebilen ve sub-klinik seyreden varikosellerin tanısına yardımcı olur. Ultrasonografi aynı zamanda tedavi öncesi ve sonrası testis boyut değerlendirmesinde de yararlıdır, zira varikosel testis hacminde azalmaya neden olabilir. Varikoselin büyüklüğü ile infertiliteye yol açan testis harabiyetinin derecesi arasında zayıf bir korelasyon mevcuttur. ${ }^{3}$

Varikosel çok uzun yıllardan beri bilinmesine rağmen patofizyolojisi tam olarak aydınlatılmış değildir. Reaktif oksijen türleri birçok oksidatif biyokimyasal ve fizyolojik işlemin yan ürünleridir ve varikosel patofizyoloji ile ilgisi de bilinmektedir. Kandaki oksidatif stresin doğrudan ölçülmesini sağlayan hiçbir biyokimyasal belirteç bulunmamasına rağmen, eritrosit dağılım genişliği (RDW) oksidatif stresi yansitan dolaylı bir belirteçtir. ${ }^{5}$ Yüksek RDW değerleri, kardiyovasküler hastalıkta hem mikro hem de makrovasküler komplikasyonların görülme sıklığı ile ilişkilidir ve mortalite ve morbiditeyi öngörmek için kullanılır. ${ }^{6}$ Daha yüksek ortalama platelet hacmi (MPV) değerleri varikosele bağlıdır. ${ }^{7,8}$ Platelet dağılım genişliği (PDW), trombosit popülasyonunun ortalama hacminin değişim katsayısı olarak hesaplanır. Yüksek PDW, trombositlerin hacim olarak normalden daha değişken olduğunu gösterir. ${ }^{9}$ Önceki çalışmalar, büyük trombositlerin, küçük trombositlere göre metabolik ve enzimatik olarak daha aktif olduğunu göstermiştir. ${ }^{10}$

Varikosel ve diğer vasküler sistem bozuklukları arasındaki potansiyel ilişki, kronik vasküler risk göstergesi olarak varikosel ve PDW, RDW ve MPV arasındaki ilişkinin araşt1rılabileceği bir çalışma yapmamızı sağlamıştır.

Çalışmamızda varikosel tanısı alan hastaların antekubital venlerinden alınan kan örnekleri ile varikosel tanısı almamış normal kişilerden alınan venöz kan örnekleri kullanılarak, kan sayım parametrelerinin düzeyleri karşılaştırılmıştır. Bu suretle, varikoselin kan sayım parametreleri üzerine olan etkileri üzerinden patofizyolojisi hakkında literatüre katkı sağlamak amaçlanmıştır.

\section{GEREÇ ve YÖNTEMLER}

Ordu Üniversitesi Eğitim ve Araştırma Hastanesi üroloji polikliniğine Nisan 2014-Nisan 2019 tarihleri arasında müracaat eden ve retrospektif olarak değerlendirilen hastalar ile ilgili araştırmamız kesitsel türde epidemiyolojik bir çalışma olarak tasarlanmıştır. Fizik muayenesinde Grade 3 varikosel tanısı konulan, yaşı 20-30/yıl arasında değişen ve sistemde hemogram sonuçlarına ulaşlabilen 163 hasta çalışmaya dahil edildi. Bilinen kronik hastalığı olanlar, hemogram alındığı dönemde parametrelerde değişikliğe yol açabilecek akut enfeksiyon tablosu olanlar, tanımlanan yaş grubunun dışında kalanlar çalışmaya dahil edilmedi. Dahil etme kriterlerini karşılayan toplam 112 hasta kontrol grubu olarak çalışmaya alındı. Varikosel fizik muayene ile değerlendirildi. Dubin ve Amelar tarafından tanımlandığı şekilde hasta ayakta duruyorken skrotum cildinden spermatik kordda dilate venlerin belirgin olarak görülüyor olması Grade 3 varikosel olarak değerlendirildi. ${ }^{11}$ Varikoselektomi ameliyatı planlanan hastalara anestezi hazırlık tetkikleri esnasında bakılan hemogram sonuçları değerlendirildi. Kontrol grubu yaş grubu benzer, bilinen kronik hastalığı olmayan, muayene ve tetkikleri sonucunda patoloji saptanmamış olan skrotal ağrı, yan ağrısı vb. nonspesifik semptomları olan hastalardan oluşuyordu. Elde edilen hemogram sonuçlarındaki beyaz kan hücresi (WBC), He- 
moglobin (HGB), Hematokrit (HCT) (\%), Platelet (PLT) $(\mathrm{mm} 3 / \mathrm{uL})$, Eritrosit (mm6/uL), Nötrofil (mm3/uL), Lenfosit (mm3/uL), Monosit (mm3/uL), Ortalama eritrosit hacmi (MCV) (fL), Ortalama hemoglobin miktarı (MCH) (pg), Eritrosit dağılım genişliği (RDW) (\%), Platelet dağ1lım genişliği (PDW) (fL), Ortalama platelet hacmi (MPV) (fL)) değerleri karşılaştırıldı. Tam kan sayımı sonucu elde edilen parametrelerden ayrıca Nötrofil/Lenfosit, Monosit/ Lenfosit, PLT/Lenfosit ve MPV/PLT oranları karşılaştırıldı. Çalışmanın etik izni Ordu Üniversitesi Tıp Fakültesi Klinik Araştırmalar Etik Kurulu'ndan 25/04/2019 tarih ve 2019/61 karar sayısı ile alındı.

\section{İstatiksel Değerlendirme}

Numunelerden elde edilen veriler, istatistik Paket Programı (SPSS 15.0) aracılığıyla bilgisayar ortamına aktarılmış ve her bir değişken için ilgili analizler yapılmıştır. Elde edilen verilere dağılım analizine göre student T ve Mann-Whitney U testleri uygulanmış ve veriler sıralanarak karşılaştırma yapılmıştır. Çalışmamızda gruplara ait sonuçlar ortalama \pm standart sapma (Ort \pm SS) olarak verilmiştir. $\mathrm{P}<0.05$ anlamlılık düzeyi olarak belirlenerek karşılaştırmalar sorgulanmıştır.

\section{BULGULAR}

Varikosel ve kontrol grubuna ait kan sayım parametrelerinin karşılaştırılması tablo 1'de gösterilmektedir. Her iki grup arasında yaş ortalamaları açısından istatistiksel farklılık saptanmamıştır ( $\mathrm{p}=0,370)$. Her iki grup arasında istatistiksel olarak anlamlı çıkan parametreler sırasıyla eritrosit sayısı $(\mathrm{p}=0,027), \operatorname{MCV}(\mathrm{p}=0,038), \operatorname{RDW}(\mathrm{p}=0,013)$ ve $\mathrm{PDW}(\mathrm{p}=0,000)$ 'dır. MPV değeri kontrol grubuna göre varikosel grubunda istatistiksel anlamlılık olmasa da rakamsal olarak kontrol grubuna göre yüksek bulunmuştur. Diğer parametreler ve oranlar arasında istatistiksel açıdan anlamlı bir farklılık saptanmamıştır.

\begin{tabular}{|c|c|c|c|}
\hline \multicolumn{4}{|c|}{$\begin{array}{l}\text { Tablo 1: Varikosel olan ve olmayan gruplar arasında yaş ve kan } \\
\text { parametrelerinin karşılaştırılması }\end{array}$} \\
\hline Değișkenler & $\begin{array}{l}\text { Kontrol } \\
(n=70) \\
\text { Ort } \pm \text { SS }\end{array}$ & $\begin{array}{l}\text { Varikosel } \\
(n=112) \\
\text { Ort } \pm \text { SS }\end{array}$ & $\mathbf{P}$ \\
\hline Yaş (yıl) & $24,49 \pm 2,63$ & $24,96 \pm 3,84$ & 0,370 \\
\hline $\mathrm{WBC}(\mathrm{mm} 3 / \mathrm{uL})$ & $6,93 \pm 1,75$ & $7,02 \pm 1,58$ & 0,758 \\
\hline $\mathrm{HGB}(\mathrm{g} / \mathrm{dl})$ & $15,13 \pm 1,30$ & $15,24 \pm 1,24$ & 0,583 \\
\hline HCT (\%) & $45,14 \pm 3,67$ & $45,37 \pm 3,44$ & 0,673 \\
\hline PLT (mm3/uL) & $245,18 \pm 61,46$ & $245,02 \pm 54,43$ & 0,985 \\
\hline Eritrosit $(\mathrm{mm} 6 / \mathrm{uL})$ & $5,19 \pm 0,46$ & $5,34 \pm 0,43$ & $0,027^{*}$ \\
\hline Nötrofil (mm3/uL) & $4,10 \pm 1,55$ & $4,24 \pm 1,34$ & 0,510 \\
\hline Lenfosit (mm3/uL) & $2,46 \pm 1,92$ & $2,11 \pm 0,52$ & 0,073 \\
\hline Monosit (mm3/uL) & $0,50 \pm 0,71$ & $0,37 \pm 0,11$ & 0,680 \\
\hline $\mathrm{MCV}(\mathrm{fL})$ & $87,23 \pm 5,64$ & $85,25 \pm 6,5$ & $0,038^{*}$ \\
\hline $\mathrm{MCH}(\mathrm{pg})$ & $29,25 \pm 2,22$ & $28,64 \pm 2,60$ & 0,108 \\
\hline RDW (\%) & $13,06 \pm 1,21$ & $13,53 \pm 1,24$ & $0,013^{\star}$ \\
\hline PDW (fL) & $26,06 \pm 16,14$ & $38,84 \pm 17,24$ & $0,000^{* * *}$ \\
\hline MPV (fL) & $8,34 \pm 1,17$ & $9,82 \pm 10,78$ & 0,758 \\
\hline Nötrofil/Lenfosit & $1,92 \pm 0,87$ & $2,11 \pm 0,87$ & 0,147 \\
\hline Monosit/Lenfosit & $0,22 \pm 0,26$ & $0,18 \pm 0,05$ & 0,131 \\
\hline PLT/Lenfosit & $114,15 \pm 39,39$ & $122,97 \pm 42,32$ & 0,162 \\
\hline MPV/PLT & $0,03 \pm 0,01$ & $0,04 \pm 0,03$ & 0,321 \\
\hline \multicolumn{4}{|c|}{$\begin{array}{l}\text { WBC: Beyaz kan hücresi, HGB: Hemoglobin, HCT: Hematokrit, } \\
\text { MCV: Ortalama eritrosit hacmi, PLT: Platelet, RDW: Eritrosit } \\
\text { dağılım genişliği, PDW: Platelet dağılım genişliği, MPV: Ortalama } \\
\text { platelet hacmi, SS: Standart sapma }\end{array}$} \\
\hline
\end{tabular}

\section{TARTIŞMA}

Çalışmamız sonucunda eritrosit sayısı, PDW ve RDW değerleri kontrol grubuna göre varikosel tanılı hastalarda oldukça yüksek MCV değeri ise düşük bulunmuştur. MPV değeri varikosel tanılı hastalarda yüksek çıkmasına rağmen sonuçlar istatistiksel olarak anlamlı bulunmamıştır. Bu sonuçlar RDW ve özellikle PDW'nin varikosel için belirleyici olabileceğini düşündürmektedir.

Artmış platelet aktivitesinin etkisi öncelikle vasküler hastalıklarda araştırılmıştır. ${ }^{12,13}$ Ayrıca, diğer çalışmalar yüksek MPV'nin ailesel Akdeniz ateşi, Behçet hastalığı ve Alzheimer hastalığı ile ilişkili olduğunu göstermiştir. ${ }^{14,15}$ Cüce ve ark.'nın yaptığı çalışmada MPV değerleri varikosel tanılı hastalarda anlamlı derecede yüksek bulunmuştur. ${ }^{16}$ 
Bozkurt ve ark. varikosel grubundaki MPV değerlerinin kontrol grubundan anlamlı olarak yüksek olduğunu rapor etmişlerdir. ${ }^{8}$ Pyo ve ark. varikosel hastalarının MPV değerlerinin sağlıklı bireylerden anlamlı derecede yüksek olduğunu bildirmişlerdir. Ancak PDW değerleri açısından anlamlı farklılık saptanmamıştır. ${ }^{17}$ Polat ve ark.nın yaptığı çalışmada MPV ve PDW değerleri açısından kontrol grubuyla varikosel grubu arasından anlamlı farklılık saptanmamıştır. ${ }^{18}$ Fakat Çoban ve ark. MPV’nin cerrahi sonrası anlamlı şekilde azaldığını bildirmiştir. ${ }^{7}$ Bizim çalışmamızda ise PDW değerleri varikosel grubunda anlamlı yüksek bulunmuş olup MPV değerleri varikosel grubunda sayısal olarak yüksek olmasına rağmen bu yükseklik istatistiksel olarak anlamlı bulunmamıştır.

Literatürde, oksidatif stresin, aterosklerotik hastalığın ilerlemesinde kilit rol oynayan vasküler inflamasyonu tetiklediği bildirilmektedir. ${ }^{19,20}$ Doğrudan ve inflamasyona bağlı olarak sitokinlerin salınması yoluyla meydana gelen oksidatif stres eritrositlere zarar verir ve eritrosit sağ kalımında azalmaya yol açarak RDW'de artışla sonuçlanan anemiye sebep olur. ${ }^{21,22}$ Hala oksidatif stresin basit ve doğrudan ölçümünü sağlayan klinik bir biyomarkır yoktur. RDW, oksidatif stres ve inflamasyonu yansitan dolaylı bir işarettir. ${ }^{5}$ Daha önceki çalışmalarda, RDW'nin çeşitli popülasyonlarda kardiyovasküler hastalık morbidite ve mortalitesi için bir belirteç olarak rol oynadığ belirtilmiştir. $^{23,24}$ Malandrino ve ark. RDW’yi erişkin diyabet popülasyonunun ulusal temsili bir örneğinde makrovasküler ve mikrovasküler komplikasyonların bir belirteci olduğunu rapor etmişlerdir. Bununla birlikte RDW’nin diyabette vasküler komplikasyonların önemli bir klinik belirteci olabileceğini ve RDW seviyelerinin yüksek olması durumunda kardiyovasküler hastalık semptomları olmadan dislipidemi, hipertansiyon ve albuminürinin yakından izlenebileceğini belirtmişlerdir. ${ }^{25}$ Çalışmamızda varikoseli olan hastaların, sağlıklı gruba göre istatistiksel olarak anlamlı derecede yüksek RDW değerlerine sahip olduğunu bulduk. Bu bilgiler ışığında çalışmamız, RDW’nin venöz hastalık tanısında kullanılabilecek bir biyobelirteç olarak kullanılabileceğini düşündürmektedir.

\section{SONUÇ}

Çalışmamız varikoseli olan hastalarda eritrosit sayısı, PDW ve RDW değerlerinin kontrole göre daha yüksek olduğunu göstermektedir. Trombosit ve eritrosit aktivasyonunun, varikoselin patofizyolojik temelinde önemli bir rol oynayabileceğini düşünmekteyiz. Ancak bu çalışma kesitseldir ve nedensellik olduğunu doğrulayamamaktadır. Bu nedenle, bu ilişkiyi doğrulamak için ileriye dönük büyük ve geniş çaplı araştırmalara ihtiyaç vardır.

Çalışmanın etik izni Ordu Üniversitesi Tıp Fakültesi Klinik Araştırmalar Etik Kurulu'ndan 25/04/2019 tarih ve 2019/61 karar sayısı ile alındı. 
Sakarya Tip Dergisi 2020;10(4):587-591

ASLAN ve Ark., Varikosel Hastalarında Kan Sayım Parametreleri

Kaynaklar

1. Noske HD, Weidner W. Varicocele--a historical perspective. World journal of urology 1999;17:151-7.

2. Beddy P, Geoghegan T, Browne RF, Torreggiani WC. Testicular varicoceles. Clinical radiology 2005;60:1248-55.

3. Zucchi A, Mearini L, Mearini E, Fioretti F, Bini V, Porena M. Varicocele and fertility: relationship between testicular volume and seminal parameters before and after treatment. Journal of andrology 2006;27:548-51.

4. Gonda RL, Jr., Karo JJ, Forte RA, O'Donnell KT. Diagnosis of subclinical varicocele in infertility. AJR American journal of roentgenology 1987;148:71-5.

5. Semba RD, Patel KV, Ferrucci $L$, et al. Serum antioxidants and inflammation predict red cell distribution width in older women: the Women's Health and Aging Study I. Clin Nutr 2010;29:600-4.

6. Tsuboi S, Miyauchi K, Kasai T, et al. Impact of red blood cell distribution width on long-term mortality in diabetic patients after percutaneous coronary intervention. Circulation journal : official journal of the Japanese Circulation Society 2013;77:456-61.

7. Coban S, Keles I, Biyik I, et al. Is there any relationship between mean platelet volume and varicocele? Andrologia 2015;47:37-41.

8. Bozkurt Y, Soylemez H, Sancaktutar AA, et al. Relationship between mean platelet volume and varicocele: a preliminary study. Urology 2012;79:1048-51.

9. Hong H, Xiao W, Maitta RW. Steady increment of immature platelet fraction is suppressed by irradiation in single-donor platelet components during storage. PloS one 2014;9:e85465.

10. Nena E, Papanas N, Steiropoulos P, et al. Mean Platelet Volume and Platelet Distribution Width in non-diabetic subjects with obstructive sleep apnoea syndrome: new indices of severity? Platelets 2012;23:447-54.

11. Dubin L, Amelar RD. Varicocele size and results of varicocelectomy in selected subfertile men with varicocele. Fertility and sterility 1970;21:606-9.

12. Huczek Z, Kochman J, Kowara MK, et al. Baseline platelet indices and bleeding after transcatheter aortic valve implantation. Blood coagulation \& fibrinolysis : an international journal in haemostasis and thrombosis 2015;26:527-32.

13. Icli A, Aksoy F, Nar G, et al. Increased Mean Platelet Volume in Familial Hypercholesterolemia. Angiology 2016;67:146-50.

14. Arica S, Ozer C, Arica V, Karakus A, Celik T, Gunesacar R. Evaluation of the mean platelet volume in children with familial Mediterranean fever. Rheumatology international 2012;32:3559-63.
15. Yesil Y, Kuyumcu ME, Cankurtaran $M$, et al. Increased mean platelet volume (MPV) indicating the vascular risk in Alzheimer's disease (AD). Archives of gerontology and geriatrics 2012;55:257-60.

16. Cuce F, Demiray O, Kucuk U, Olgun Kucuk H. Varicocele: tissue stress in the etiology. Turkish journal of medical sciences 2016;46:1014-7.

17. Pyo JS, Cho WJ. Mean Platelet Volume, Platelet Distribution Width, and Platelet Count in Varicocele: A Systematic Review and Meta-Analysis. Cellular physiology and biochemistry: international journal of experimental cellular physiology, biochemistry, and pharmacology 2016;38:2239-46.

18. Polat H, Gulpinar MT, Sarica MA, Benlioglu C. Relationship between mean platelet volume, platelet distribution width, plateletcrit and varicocele. Andrologia 2017;49.

19. May JE, Marques MB, Reddy VVB, Gangaraju R. Three neglected numbers in the CBC: The RDW, MPV, and NRBC count. Cleveland Clinic journal of medicine 2019;86:167-72.

20. King GL, Loeken MR. Hyperglycemia-induced oxidative stress in diabetic complications. Histochemistry and cell biology 2004;122:333-8.

21. Friedman JS, Lopez MF, Fleming MD, et al. SOD2-deficiency anemia: protein oxidation and altered protein expression reveal targets of damage, stress response, and antioxidant responsiveness. Blood 2004;104:2565-73.

22. Lippi G, Targher G, Montagnana M, Salvagno GL, Zoppini G, Guidi GC. Relation between red blood cell distribution width and inflammatory biomarkers in a large cohort of unselected outpatients. Archives of pathology \& laboratory medicine 2009; 133:628-32.

23. Patel KV, Ferrucci L, Ershler WB, Longo DL, Guralnik JM. Red blood cell distribution wi$d$ th and the risk of death in middle-aged and older adults. Archives of internal medicine 2009; 169:515-23.

24. Perlstein TS, Weuve J, Pfeffer MA, Beckman JA. Red blood cell distribution width and mortality risk in a community-based prospective cohort. Archives of internal medicine 2009;169:588-94.

25. Malandrino N, Wu WC, Taveira TH, Whitlatch HB, Smith RJ. Association between red blood cell distribution width and macrovascular and microvascular complications in diabetes. Diabetologia 2012;55:226-35. 